\title{
Pengembangan Media Pembelajaran E-Learning Berbasis Schoology
}

\author{
Edi Supratman $^{1 *}$ ), Fitri Purwaningtias ${ }^{2}$ \\ ${ }^{1}$ Program studi Teknik Informatika, Fakultas Ilmu Komputer, Universitas Bina Darma, Palembang \\ ${ }^{2}$ Program Studi Sistem Informasi, Fakultas Ilmu Komputer, Universitas Bina Darma, Palembang \\ ${ }^{1,2}$ Jln. Jendral Ahmad Yani No.3 Plaju, Kota Palembang, 30264, Indonesia \\ email: 1edi_supratman@binadarma.ac.id, ${ }^{2}$ fitri.purwaningtias@binadarma.ac.id
}

\author{
Received: 15 Juli 2018; Revised: 1 Oktober 2018; Accepted: 20 Oktober 2018 \\ Copyright $@ 2018$, Politeknik Harapan Bersama, Tegal
}

\begin{abstract}
Learning with the E-learning method is learning by using technology because online e-learning uses computer networks to provide information and communication. Where with the use of e-learning can occur changes in learning activities between teachers and students and students can learn wherever and whenever. SUMSEL N HIGH SCHOOL (Sampoerna Academy) Palembang has a vision that is international level and has the hope to become an example for other national schools by implementing international standards and has a mission to make students global in mind. In the SUMSEL High School in the learning process still using conventional learning methods through face-to-face in class, the provision of subject matter is carried out only in class and also if the teacher is not entered, the subject material is not obtained by students. So that this research was carried out by utilizing information and communication technology in changing learning activities namely the use of school-based e-learning. While this research is research \& development research refers to the development model Analyze, Design, Develop, Implement, Evaluation (ADDIE). School-based E-learning has features similar to Facebook and schoology also combines social networks and LMS (Learning Management System). So that with schoology-based e-learning can get information about the subject matter that is given by the teacher easily even though the teacher is unable to attend the class because through schoology the teacher can attend student attendance, and between the teacher and students can interact socially while learning.
\end{abstract}

Abstrak - Pembelajaran dengan metode E-learning adalah pembelajaran dengan pemanfaatan teknologi karena secara media online e-learning menggunakan jaringan komputer untuk memberikan informasi dan komunikasi Dimana dengan penggunaan e-learning ini bisa terjadi perubahan dalam kegiatan pembelajaran diantara guru dan siswa serta siswa bisa belajar dimanapun dan

*) Corresponding author: (Edi Supratman)

Email: edi_supratman@binadarma.ac.id kapanpun. SMA N SUMSEL (Sampoerna Academy) Palembang memiliki visi yaitu bertaraf internasional dan memiliki harapan untuk menjadi contoh bagi sekolah nasional lainnya dengan mengimplementasi standar internasional dan memiliki misi untuk menjadikan peserta didik berwawasan global. Pada SMA N SUMSEL pada proses pembelajaran masih menggunakan metode pembelajaran yang konvensional melalui tatap muka di kelas, pemberian materi pelajaran dilakukan hanya dikelas dan juga jika guru tidak masuk maka materi pelajaran tidak diperoleh siswa. Sehingga penelitian ini dilakukan dengan memanfaatkan teknologi informasi dan komunikasi dalam perubahan kegiatan pembelajaran yaitu penggunaan e-learning berbasis schoology. Sedangkan penelitian ini merupakan penelitian research \& development mengacu dengan model pengembangan Analyze, Design, Develop, Implement, Evaluation (ADDIE). E-learning berbasis schoology memiliki fitur mirip dengan facebook dan schoology juga menggabungkan antara jejaring sosial dan LMS (Learning Management System). Sehingga dengan e-learning berbasis schoology bisa memperoleh informasi materi pelajaran yang diberikan guru dengan mudah meskipun guru berhalangan hadir di kelas karena melalui schoology guru bisa mengabsen kehadiran siswa, serta antara guru dan siswa bisa berinteraksi sosial sekaligus belajar.

\section{Kata Kunci - E-Learning, Schoology, Research \& Development}

\section{PENDAHULUAN}

Sekolah SMA Negeri SUMSEL Palembang yang dulunya bernama Sampoerna Academy merupakan salah satu sekolah terbaik di Palembang. Karena sekolah ini membantu anakanak yang orang tuanya kurang mampu untuk membiayai sekolah ke jenjang SMA. Sekolah ini memberikan sekolah gratis kepada anak yang pintar tetapi memiliki perekonomian yang kurang mampu. Tetapi kenyataannya bahwa pada media pembelajaran di sekolah SUMSEL masih menggunakan media pembelajaran secara tatap muka antara guru dan siswa di kelas. Aktivitas belajar merupakan proses perubahan perilaku akibat interaksi individu dengan lingkungan [1]. Dari 
aktivitas belajar inilah bisa menjadi motivasi belajar siswa merupakan dorongan internal dan eksternal pada diri siswa yang sedang belajar untuk mengadakan perubahan tingkah laku dengan beberapa indikator atau unsur mendukung [2].

Dengan permasalahan yang ada, dibutuhkan support guna tetap menjadi sekolah yang memiliki kualias yang baik dengan cara merubah gaya belajar sehingga bisa menarik bagi siswa dan menjadi semangat belajar karena perubahan paradigma tercermin dalam perubahan pandangan dimana guru dan siswa memiliki peran penting dalam kegiatan pembelajaran [3], salah satunya media pembelajaran menggunakan e-learning yaitu berupa instruksi yang disampaikan melalui media digital seperti komputer atau perangkat mobile untuk mendukung pembelajaran [4]. Elearning memiliki empat karakteristik yaitu: 1) memanfaatkan jasa teknologi elektronik; 2) memanfaatkan keunggulan komputer; 3) menggunakan bahan ajar bersifat mandiri. Keempat memanfaatkan komputer untuk menyimpan jadwal pembelajaran, hasil belajar dan hal-hal yang berkaitan dengan administrasi pembelajaran [5]. Selain karakteristik, e-learning juga memiliki manfaat sebagai suplemen (tambahan), sebagai komplemen (pelengkap) dan sebagai substitusi (pengganti) [6]. Saat ini sekolah SMAN SUMSEL belum menggunakan pemanfaatan teknologi informasi dan komunikasi berupa $e$ learning tersebut untuk melakukan perubahan media pembelajaran seperti sekolah lainnya. Dikarenakan pihak sekolah kurangnya pengetahuan untuk bisa mengembangkan kegiatan belajar mengajar yang memanfaatkan teknologi informasi dan komunikasi dengan metode belajar yang menarik dan belum adanya untuk mendorong perubahan dalam penggunaan e-learning tersebut. Salah satu e-learning yang bisa digunakan secara open source yaitu berbasis Schoology. Schoology merupakan website yang memadukan e-learning dan jejaring sosial dan user friendly [7]. Fitur-fitur yang ada yaitu Courses untuk membuat kelas, Groups untuk kelompok, Resources berupa materi bisa juga untuk tugas, quiz, diskusi, media album [8]. Schoology juga memiliki kelebihan dari e-learning yang lain karena memiliki fasilitas Attandance untuk mengecek kehadiran siswa dan fasilitas Analytic untuk melihat aktivitas siswa setiap course, assigment, diskusi dan aktivitas lain untuk siswa [9]. Dengan adanya perubahan pada media pembelajaran menggunakan Schoology bisa membuat minat belajar siswa dan guru menjadi lebih menarik dan lebih meningkat karena fitur-fitur yang dimiliki.

Permasalahan yang ada membuat penelitian ini untuk bisa mengubah media pembelajaran dengan memanfaatkan teknologi yang ada yaitu penggunaan e-learning berbasis schoology pada SMA Negeri SUMSEL sebagai salah satu media pembelajaran lainnya selain pembelajaran dengan tatap muka di kelas guna membuat siswa bisa belajar dimanapun dan kapanpun. Serta guru juga tetap bisa mengawasi kehadiran siswanya melalui penggunaan schoology.

\section{PENELITIAN YANG TERKAIT}

Pihak sekolah biasanya akan melakukan perubahan media pembelajaran yang digunakan untuk mengikuti perkembangan dunia digital berupa rancangan aplikasi sistem E-learning berbasis web untuk meningkatkan motivasi belajar guru dan siswa yang diharapkan bisa menunjang proses belajar mengajar dan penyampaian informasi kepada siswa secara cepat dengan informasi terkini [10]. Kemudian di kajian lain mengatakan bahwa e-learning yang biasa pihak sekolah biasanya digunakan yaitu edmodo dan schoology, hanya saja keduanya memiliki perbedaan dalam tingkat motivasi belajar bagi siswa. Kelas yang menggunakan $e$ learning berbasis schoology menyatakan bahwa siswa menjadi lebih termotivasi daripada kelas yang menggunakan edmodo karena schoology mudah diakses dan peserta didik juga mempunya target nilai. Selain itu dengan schoology siswa lebih memahami pelajaran serta lebih aktif dalam pembelajaran. Sehingga menyebabkan siswa menjadi lebih semangat, lebih senang dan bisa belajar dimanapun [11].

Selanjutnya kajian lain juga menyatakan bahwa dengan adanya penggunaan e-learning berbasis schoology mendapat respon yang baik dari siswa disetiap aspek keseluruhan schoology karena schoology termasuk dalam kategori sangat menarik untuk pembelajaran [12]. Kajian lain juga menyatakan bahwa dengan schoology memberikan pengaruh nilai siswa meningkat [13]. Berdasarkan beberapa kutipan diatas bahwa dengan media pembelajaran e-learning bisa meningkatkan minat belajar siswa. Apalagi dengan penggunaan e-learning berbasis schoology ini selain siswa bisa belajar kapanpun dan dimanapun, dengan schoology juga membuat siswa dan guru bisa berinteraksi sosial karena di fitur schoology memiliki tautan untuk berbagai sosial media dan guru juga bisa melihat kehadiran siswa serta mengontrol kegiatan yang dilakukan siswa selama menggunakan schoology.

\section{METODE PENELITIAN}

Penelitian ini merupakan metode research \& development mengacu pada model pengembangan ADDIE (Analyze, Design, Develop, Implement, Evaluation). Model ini uraiannya lebih lengkap dan sistematis serta model pengembangan yang mengakomodasi tentang IT [14].

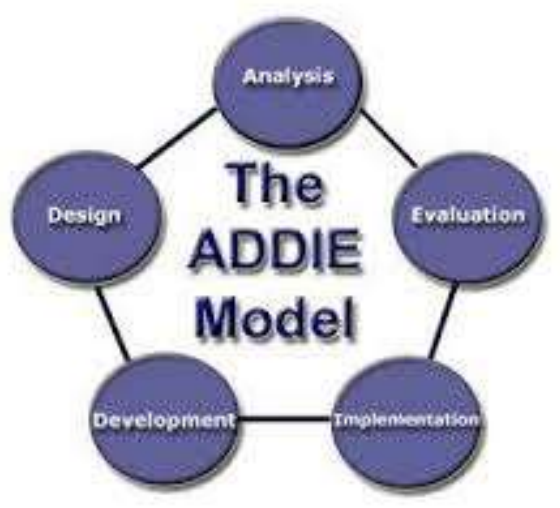

Gbr.1 Tahapan ADDIE

Berdasarkan pada Gbr.1 tahapan yang dilakukan pada penelitian ini diantaranya yaitu:

1) Tahap Analyze

Pada tahapan ini dilakukan analisis kebutuhan dan identifikasi masalah. Peneliti melakukan observasi pada sekolah SMA Negeri SUMSEL dan juga melakukan interview dengan pihak sekolah yaitu dengan Kepala Sekolah dan juga Wakil Kepala Sekolah Bagian Kurikulum tentang bagaimana pembelajaran selama ini dilakukan oleh pihak sekolah dengan siswa. Hasil dari interview tersebut 
didapatkan bahwa cara pembelajaran di sekolah masih dilakukan secara tatap muka di kelas antara guru dan siswa dan siswa hanya mendapatkan pembelajaran dikelas saja dan membawa PR kerumah. Sehingga dari cara pembelajaran dan media pembelajaran itulah membuat materi yang diajarkan terbatas karena materi tidak selesai diajarkan dikarenakan waktu yang terkadang libur ataupun guru berhalangan hadir. Apalagi siswa kelas 12 pembelajarannya di lanjutkan sampai malam karena adanya pelajaran tambahan untuk persiapan UN dan untuk mengikuti tes perguruan tinggi ataupun beasiswa di Universitas. Sehingga bisa menyebabkan kepenatan siswa untuk belajar dan kelelahan dalam belajar. Oleh karena itulah SMA Negeri SUMSEL memerlukan pengembangan untuk sistem pembelajaran di sekolah agar bisa pembelajaran dapat dilakukan dengan lebih baik lagi meskipun saat pembelajaran tersebut guru berhalangan hadir baik dikarenakan guru sedang rapat ataupun alasan lainnya sehingga siswa bisa mendapatkan pembelajaran dimana saja dan kapan saja bisa belajar meskipun bukan dikelas, maka diperlukan inovasi pembelajaran bagi siswa dan guru yaitu dengan adanya e-learning. Karena selama ini pihak sekolah belum adanya inisiatif untuk melakukan perubahan inovasi pembelajaran menggunakan e-learning dan juga kurangnya pengetahuan dari pihak sekolah untuk bisa membuat $e$ learning berbasis schoology.

\section{2) Tahap Design}

Selanjutnya tahap design ini membuat rancangan dengan merumuskan tujuan pembelajaran dan strategi pembelajaran yang tepat untuk mencapai tujuan. Setelah dilakukannya analyze maka peneliti merancang untuk membuat perubahan media pembelajaran menggunakan e-learning berbasis schoology yang cocok untuk digunakan pihak sekolah. Dengan schoology ini yang memiliki banyak fitur baik itu adanya media sosial didalamnya yang mana siswa lebih menyukai untuk bisa menggunakan media sosial sehingga bisa berkomunikasi antara guru dan siswa serta guru juga melalui schoology bisa mengontrol kegiatan yang dilakukan siswa dan kehadiran siswa. Pada schoology ini nantinya akan disesuaikan dengan mata pelajaran dan materi yang diadopsi dari sekolah sebagai panduan untuk membuat bahan ajar.

\section{3) Tahap Development}

Pengembangan merupakan proses untuk mewujudkan menjadi kenyataan. Development ini untuk membuat dan memanfaatkan e-learning berbasis schoology pada sekolah SMA N SUMSEL. Pada tahap ini menganalisis pengguna sistem dan apa saja yang bisa dilakukan pengguna. Pengguna sistem pada e-learning berbasis schoology yaitu guru dan siswa.. Pengguna sebagai guru bisa membuat kategori,, mengorganisasi isi baik mengupload materi, memberikan tugas, menilai tugas, memantau perkembangan pembelajaran siswa dengan berdiskusi di forum atau sosial media. Sedangkan sebagai siswa bisa melihat materi, mengupload tugas, berdiskusi dalam forum ataupun bisa bersosial media. Perancangan untuk membuat diagram alir data untuk menggambarkan kerja sistem yang dilakukan menggunakan DFD (Data Flow Diagram) yaitu refresentasi grafik yang menggambarkan aliran informasi dan transformasi informasi yang diaplikasikan sebagai data yang mengatur dari masukan dan keluaran[15]. Dan membuat tampilan cara penggunaan dari schoology.

\section{4) Tahap Implementation}

Setelah tahap development di buat maka penggunaan elearning berbasis schoology bisa dibuat bagaimana untuk menjadi login guru serta mendaftarkan nama sekolah pada schoology jika belum terdaftar dan login siswa serta bagaimana cara kerja schoology sebagai guru dan siswa. Untuk selanjutnya bisa diimplementasikan ke sekolah.

\section{5) Tahap Evaluasi}

Tahap implementasi selesai maka peneliti melakukan evaluasi ke sekolah untuk mendemokan penggunaan schoology kepada guru dan siswa yang ada di sekolah dan bisa mengevaluasi beberapa bulan kedepannya tentang bagaimana penggunaan schoology dilingkungan sekolah.

\section{HASIL DAN PEMBAHASAN}

Berikut adalah DFD berupa diagram konteks yang digambarkan untuk proses berjalannya sistem seperti pada Gbr.2.

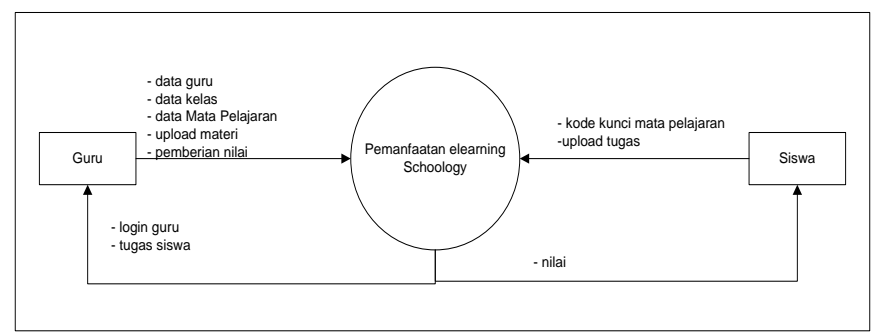

Gbr. 2 Diagram Konteks

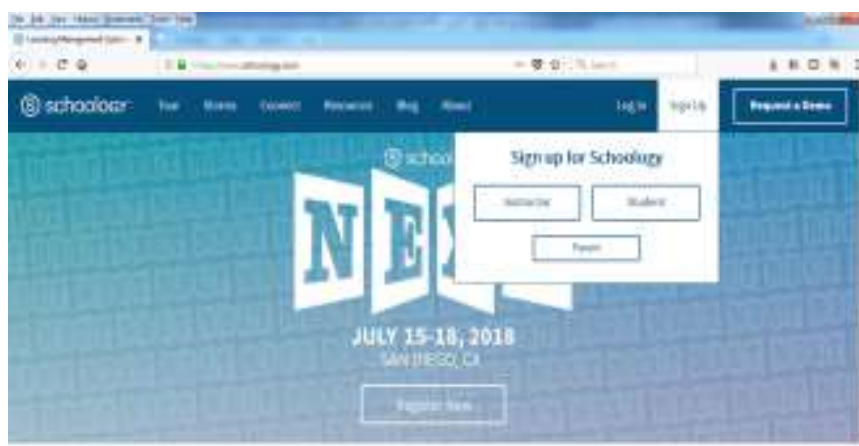

\section{Schoology /skoo-luh-jee/}

Gbr. 3 Halaman Awal Schoology

Pada Gbr.2 menjelaskan bahwa adanya dua pengguna yaitu guru dan siswa, dimana guru mengisi data guru baik itu data sekolah dimana guru mengajar, setelah berhasil mendapat login guru, guru kemudian mengisi kelas dan mata pelajaran yang diampuh dan terdapat kode kunci mata pelajaran untuk bisa diberikan ke siswa agar mengikuti kelas tersebut. Setelah selesai maka, guru bisa memberikan tugas, materi dan lain lain kepada siswa. Selanjutnya untuk siswa agar bisa mengikuti mata pelajaran sesuai dengan guru yang diampuh maka harus memasukkan kode kunci mata pelajaran. Selanjutnya baru siswa mengisi data siswa dan mengupload 
tugas yang diberi oleh guru. Setelah berhasil upload tugas maka guru bisa merespon dengan memberikan nilai kepada siswa.

Hasil dari penelitian ini yaitu berupa pemanfaatan $e$ learning berbasis schoology yang bisa diakses pada www.schoology.com. Pada schoology ini memiliki login untuk guru dan siswa.
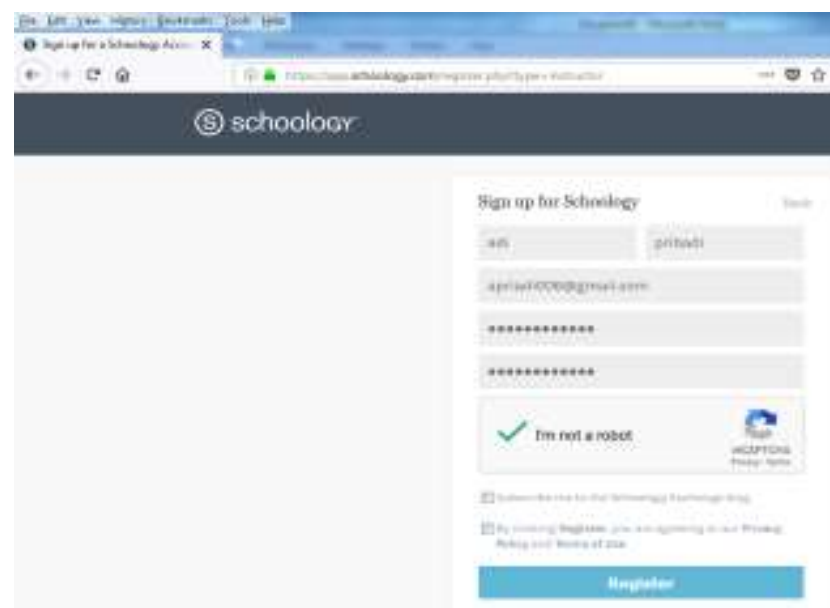

Gbr. 4 Halaman Sign Up Guru
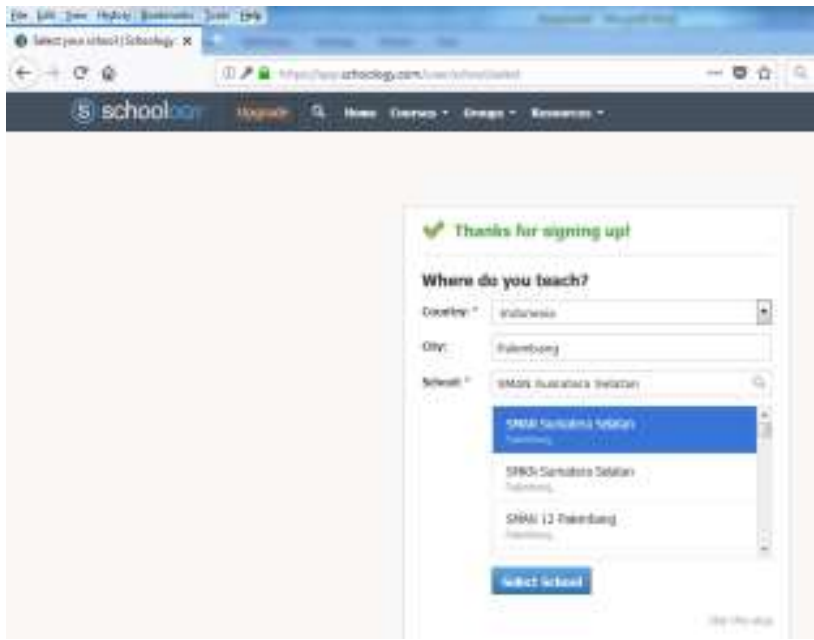

Gbr. 5 Halaman Sign Up Selanjutnya
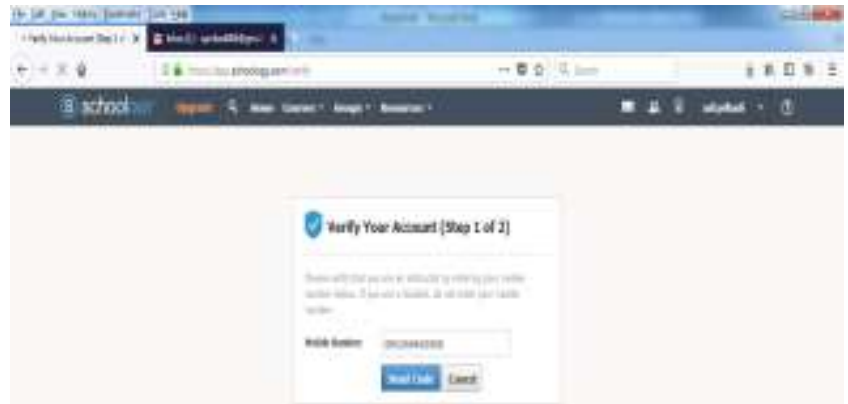

Gbr. 6 Halaman Login Guru

\section{A. Layanan Guru}

1) Halaman tampilan awal schoology

Pada Gbr 3 adalah halaman tampilan awal schoology dimana pada tampilan awal ini telah ada menu sign up sebagai guru dan siswa bagi siswa dan guru yang belum memiliki login schoology, dan menu login jika telah terdaftar sebagai siswa dan guru.

\section{2) Halaman Sign Up Guru}

Gbr 4 menjelaskan tentang guru untuk masukkan datadata guru untuk melakukan pendaftaran kemudian klik register. Setelah register akan tampil untuk mengisi data asal sekolah dan klik select school seperti pada gbr 4. Kemudian guru akan mendapatkan username dan password untuk login. Gbr 6 menjelaskan untuk login guru kemudian ada verify akun dengan nomor telepon guru sebagai verifikasi.

\section{3) Halaman Input Data Kelas dan Mata Pelajaran}

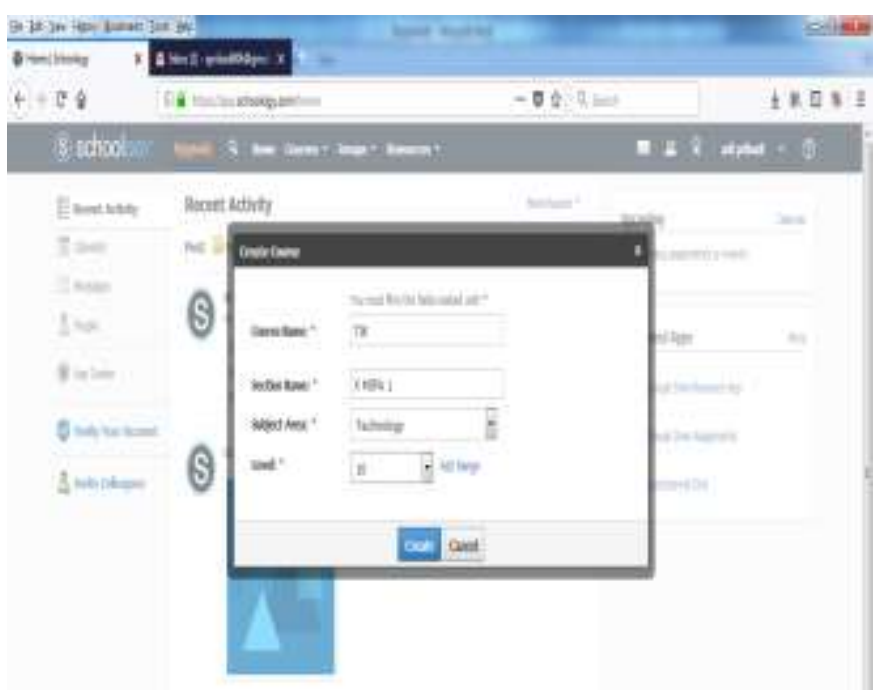

Gbr. 7 Data Kelas dan Mata Pelajaran

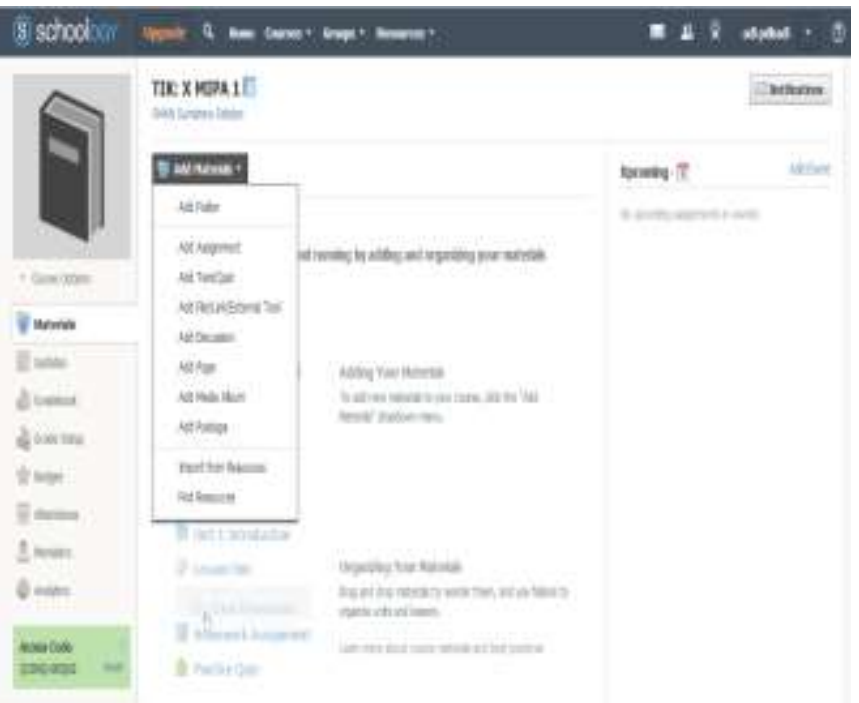

Gbr. 8 Halaman Materi/Tugas/Materi 
Pada Gbr.7 interface yang memungkinkan guru kemudian mengisi data kelas dan mata pelajaran untuk siswa bisa mengikuti mata pelajaran yang diajarkan.

\section{4) Halaman Input Materi/Tugas/Quiz}

Pada Gbr 8, halaman ini untuk memberi materi ataupun bisa untuk tugas/materi. Pada halaman ini juga terdapat access code yang ada untuk siswa nantinya mengikuti kelas dan mata pelajaran.

\section{5) Halaman Memberikan Tugas}

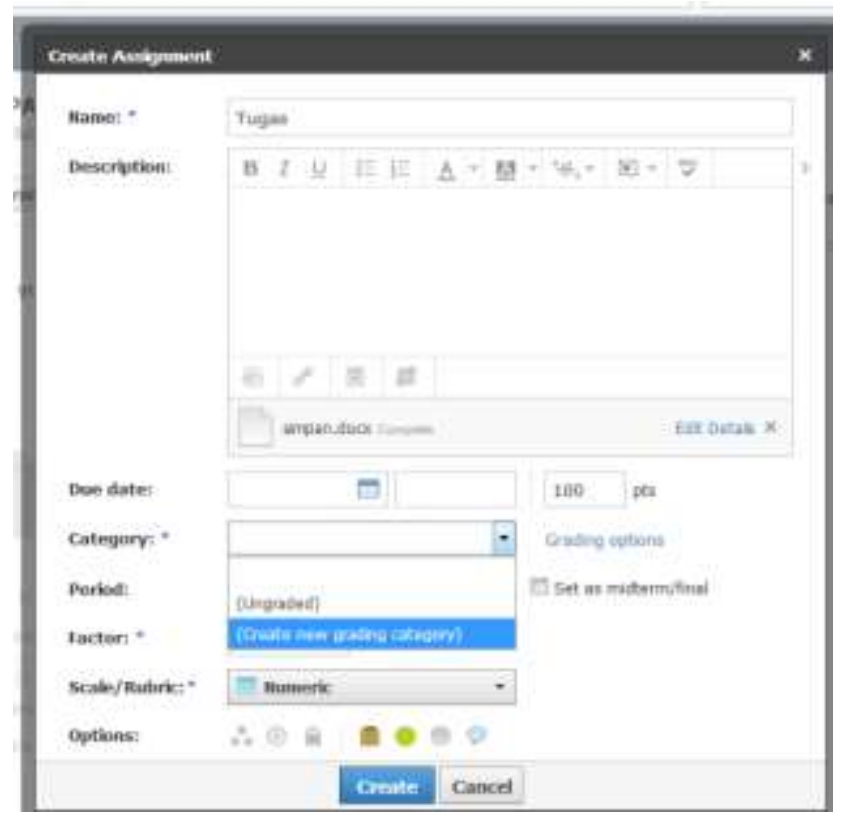

Gbr. 9 Halaman Pemberian Tugas
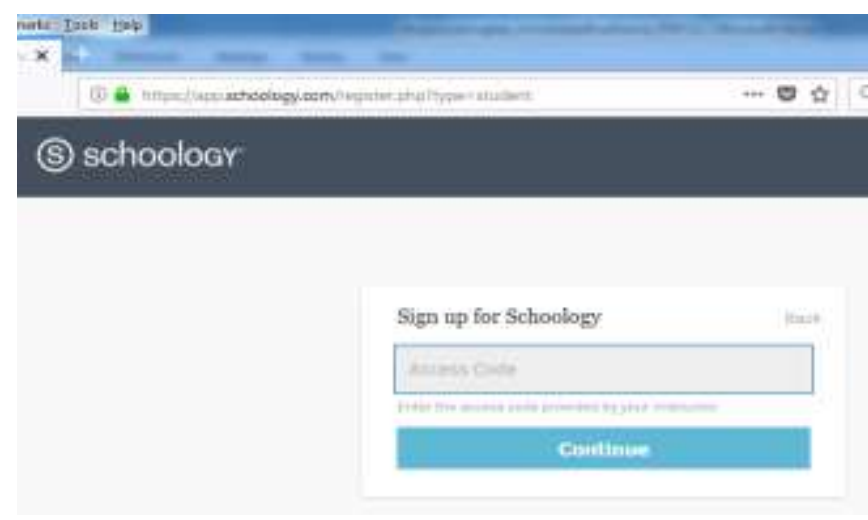

Gbr. 10 Halaman Access Code

Gbr 9 menjelaskan tentang pemberian tugas oleh guru untuk siswa dengan mengisi nama tugasya apa. Bisa untuk tugas dimasukkan dalam file. Dan juga tugasnya bisa disetting apakah untuk homework atau tidak serta durasi berapa lama pengumpulan tugas tersebut.

\section{B. Layanan Siswa}

1) Masukkan access code

Pada Gbr. 10 access code diisi dengan access code mata pelajaran dan kelas guru yang telah diberikan guru kepada siswanya.

\section{2) Halaman Sign Up Siswa}

Gbr. 11 menjelaskan untuk sign up siswa berupa data-data siswa.

\section{(9) schoology}

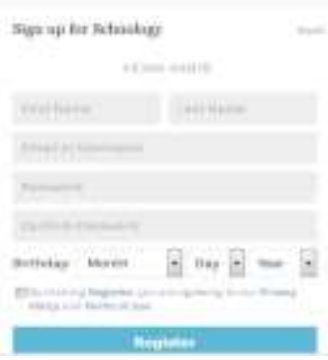

Gbr. 11 Halaman Sign up Siswa

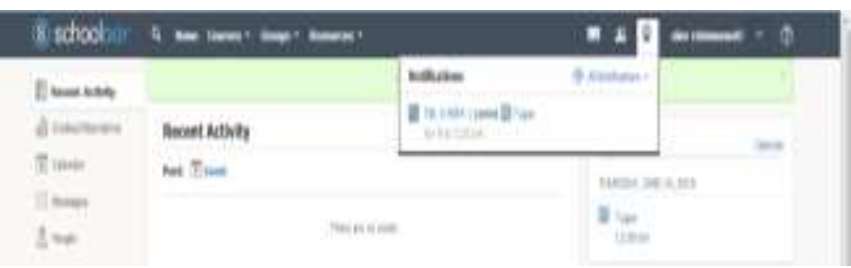

Gbr. 12 Halaman Info Tugas

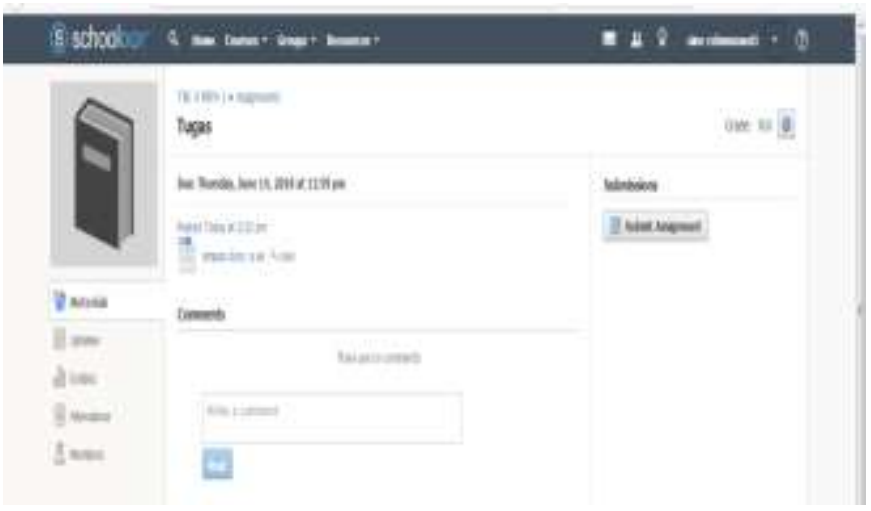

Gbr. 13 Halaman Tugas Siswa

\section{3) Halaman Info Tugas}

Untuk melihat info tugas siswa bisa melihat notifikasi sebelah kanan pada website schoology ini. Setelah itu bisa di klik kemudian akan tampil dan bisa di-download siswa apabila file dalam bentuk word ataupun pdf. Selanjutnya jika tugas/quiz selesai maka siswa bisa mengirim file kembali dengan klik submit assignment seperti Gbr 13. 


\section{KESIMPULAN}

Penelitian ini menghasilkan sebuah media pembelajaran menggunakan media digital berupa e-learning berbasis schoology sebagai inovasi pembelajaran untuk guru dan siswa. Sehingga bisa membantu guru untuk mempermudah dalam memberikan pelajaran kepada siswa yang selama ini tidak variasi. Selain itu juga untuk memotivasi siswa dalam meningkatkan pembelajaran lebih menarik dan lebih semangat lagi karena e-learning berbasis schoology memiliki banyak fitur yang akan disukai oleh siswa. E-learning berbasis schoology memiliki kekurangan yaitu untuk mengupload file bukan hanya word dan pdf agar lebih lengkap lagi dan bisa lebih bervariasi sehingga untuk peneliti selanjutnya bisa melakukan pengevaluasian terhadap penggunaan schoology ini karena penelitian ini hanya sebatas penggunaan schoology saja.

\section{DAFTAR PUSTAKA}

[1] Hartono, PAIKEM PembelajaranAktif, Inovatif, Kreatif, Efektif dan Menyenangkan, Pekanbaru: Zafana, 2008.

[2] H. B. Uno, Teori Motivasi dan Pengukurannya: Analisis di bidang Pendidikan, Jakarta: Bumi Aksara, 2011.

[3] Rusman, Belajar dan Pembelajaran berbasis Komputer: Mengembangkan Profesionalisme Abad 21, Bandung: Alfabeta, 2013.

[4] R. C. Clark dan R. E. Mayer, E-Learning and the science of instruction, Amerika: Pfeiffer, 2011.

[5] Rusman, Belajar dan Pembelajaran Berbasis Komputer, Bandung: Alfabeta, 2012.
[6] S. Siahaan, "E-learning (Pembelajaran Elektronik) sebagai Salah satu alternatif kegiatan pemebelajaran," Jurnal Pendidikan dan Kebudayaan, 2003.

[7] T. Aminoto dan H. Pathoni, "Penerapan Media E-learning Berbasis Schoology Untuk Meningkatkan Aktivitas dan Hasil Belajar MAteri Usaha dan Energi di kelas XI SMA N 10 Kota Jambi," Jurnal Pendidikan Fisika, 2014.

[8] Amiroh, "antara moodle, e dmodo dan schoology," Januari 2013. [Online]. Available: http://amiroh.web.id/antara-moodle-edmodo-danschoology. [Diakses 20 Mei 2018].

[9] S. Kosasi, "Perancangan E-learning untuk Meningkatkan Motivasi Belajar Guru dan Siswa," dalam Seminar Nasional Pendidikan Teknik Informatika, Bali, 2015.

[10] Efendi, "E-learning berbasis Schoology dan edmodo: ditinjau dari Motivasi dan Hasil Belajar Siswa SMK," ELINVO (Electronics, Informatics and Vocational Education), vol. 02, no. 01, 2017.

[11] Widiantoro dan L. Rakhmawati, "Pengembangan Media Pembelajaran E-learning Berbasis Schoology pada Kompetensi Dasar Memahami Model Atom bahan SemiKonduktor di SMKN 1 Jetis Mojokerto," JurnalPendidikan Teknik Elektro, vol. 04, no. 02, pp. 501-506, 2015.

[12] K. Murni dan R. Harimurti, "Pengaruh E-learning berbasis Schoology terhadap Peningkatan Hasil Belajar Siswa dalam Materi Perangkat Keras Jaringan Kelas X TKJ 2 pada SMK N 3 Buduran, Sidoarjo,” IT$e d u$, vol. 01, no. 01, pp. 86-90, 2016.

[13] R. A. Sukamto dan M. Salahuddin, Rekayasa Perangkat Lunak Terstruktur dan Berorientasi Objek, Bandung: Informatika, 2014.

[14] R. M. Branch, Instructional Design -The ADDIE Approach, New York: Springer, 2009.

[15] Putri, N. W. M. Ananda, N. Jampel dan I. K. Suartama, "Pengembangan E-learning Berbasis Schoology pada Mata Pelajaran IPA Kelas VIII di SMP Negeri 1 Seririt," Edutech Universitas Pendidikan Ganesha, vol. 02, no. 01, pp. 1-11, 2014. 